\title{
ROLE OF ULTRASONOGRAPHY FOR EVALUATION OF ACUTE APPENDICITIS: A UNAMID EXPERIENCE
}

\author{
Muhammad Tahsin Hashmi, Irum Taqi*, Amberin Taqi, Hassan Junaid Sarwar** \\ Combined Military Hospital Kohat/National University of Medical Sciences (NUMS) Pakistan, *PAF Hospital Islamabad Pakistan, \\ ${ }^{* *}$ Combined Military Hospital Rawalakot/National University of Medical Sciences (NUMS) Pakistan
}

\begin{abstract}
Objective: To evaluate the accuracy of ultrasound findings as compared to operative findings and positive predictive value of ultrasonography in the diagnosis of acute appendicitis.

Study Design: Cross sectional study.

Place and Duration of Study: Pak Field Hospital - 7 (Level III) United Nations African Union Mission in Darfur (UNAMID) Darfur, Sudan, from Mar 2015 to Mar 2016.

Methodology: All patients presenting with clinically suspected acute appendicitis (Alvarado's score $>4$ ) were referred for right lower quadrant sonography. Three point scale was used to grade sonographic findings ranging from grade 1 to grade 3 . Fifty One patients with persistent symptoms and/or positive sonographic findings were operated. Operative findings were also graded on a 3 point scale. Subsequently, sonographic and operative findings were compared. Surgical findings were considered gold standard to assess diagnostic accuracy of sonography.

Results: Out of 51 patients $46(90.2 \%)$ were males and 5 (9.8\%) were females. Mean age of the patients was $32.3 \pm$ 7.3 years. Among the study subjects, 15 (29.4\%) patients were from Nigeria followed by 12 (23.5\%) from Pakistan, $7(13.7 \%)$ from Egypt and 17 (33.5\%) from other countries.

The sonographic findings were detected positive for acute appendicitis in 40 (78.4\%) and negative in 11 (21.6\%) out of 51. All Fifty-one patients underwent surgery. The surgical findings were positive for appendicitis in 43 patients $(84.3 \%)$. Four patients with negative sonographic findings did have acute appendicitis according to surgical findings. The positive predictive value was $90.9 \%$. There was good agreement between sonographic findings and surgical findings, which was statistically significant. ( $\mathrm{kW}=0.70$ [95\% CI, 0.49-0.91]).

Conclusion: In our study, sonography has a high PPV and NPV. Sonography should be considered as a primary screening tool in the algorithm of evaluation of acute appendicitis.
\end{abstract}

Keywords: Appendicitis, Sonography, Operative, UNAMID.

This is an Open Access article distributed under the terms of the Creative Commons Attribution License (http://creativecommons.org/licenses/by/4.0), which permits unrestricted use, distribution, and reproduction in any medium, provided the original work is properly cited.

\section{INTRODUCTION}

Acute appendicitis is the most common diagnosis in young adults presenting with 'acute abdomen' in ER and appendicectomy is the most frequently performed urgent abdominal operation ${ }^{1}$. Although modern radiographic imaging has improved diagnostic accuracy, however the diagnosis of acute appendicitis remains essentially clinical. In 1886, Reginald Fitz presented a paper titled 'Perforating inflammation of the vermiform appendix' in the first meeting of the Association of American Physicians². Later

Correspondence: Dr Muhammad Tahsin Hashmi, Classified Surgical Specialist, Pakistan Air Force Hospital Islamabad Pakistan Received: 16 Apr 2018; revised received: 17 Nov 2020; accepted: 22 Dec 2020
Charles McBurney described the clinical manifestations of acute appendicitis ${ }^{3}$.

The individual lifetime risk of appendicectomy is $8.6 \%$ for males and $6.7 \%$ for females ${ }^{4,5}$. Acute appendicitis is common in childhood with the highest incidence in the second and third decades of life. The incidence of appendicectomies has steadily decreased in Western countries since $1990^{5}$. In the present era, In the present era, the incidence of both appendicitis and appendicectomy is high in industrialized countries in Asia, the Middle East and Southern America, probably due to increased use of diagnostic imaging with higher detection rate of mild appendicitis and an increase rate of appendicectomies for mild non-perforated appendicitis 5,6 . 
Puylaert in the 1980s described the role of ultrasonography for the diagnosis of acute appendicitis7. In 1994, study by Balthazar showed better accuracy, sensitivity and negative predictive value of computed tomography as compared to ultrasonography ${ }^{6}$. However, while CT scan is considered gold standard in the diagnosis of appendicitis, due to ionizing radiation and increased risk of malignancy, its liberal use is being questioned ${ }^{8}$. Multiple authors have proposed the use of ultrasonography as the first diagnostic modality for suspected appendicitis, with CT scan of the abdomen reserved for ultrasound negative or equivocal cases to prevent radiation exposure ${ }^{9}$. In certain populations like paediatric patients, females and thin lean patients, ultrasonography has higher reported specificity for appendicitis and it can help delineate other abdominal or pelvic pathologies ${ }^{10}$. The rationale of this study was to assess the efficacy and positive predictive value (PPV) of sonography and the correlation between operative and ultrasound findings in the diagnosis of acute appendicitis.

\section{METHODOLOGY}

A cross sectional study was conducted at Pak Field Hospital - 7 (Level III) United Nations African Union Mission in Darfur (UNAMID), Sudan, after hospital ethics committee review and formal approval. The reference prevalence of acute appendicitis was $44.272 \% 11$. Using convenience sampling technique, total 60 patients were initially included, out of which symptoms settled in 6 patients and three patients did not consent for surgery hence they were dropped out. Study was done on 51 patients with clinically suspected acute appendicitis (Alvarado score $>4$ ).

Patients of both genders and any age group presenting with acute abdominal pain with clinical diagnosis of acute appendicitis were included in study after informed written consent. The patients who refused to consent and patients unfit for anaesthesia were excluded from study. Similarly, known and newly diagnosed patients of right renal calculi, hydronephrosis and ovarian pathology on ultrasonography were also excluded.

All patients with clinically suspected acute appendicitis (alvarado score $>4$ ) were referred for sonography. Three point scale was used to grade sonographic findings namely grade 1 (Appendix not visible or normal looking), grade 2 (Inflamed appendix with diameter more than $6 \mathrm{~mm}$ ) and grade 3 (Grossly inflamed appendix with periappendicular fluid or only secondary signs of appendicitis). Fifty One patients with persistent symptoms and positive sonographic findings were operated. Operative findings were also graded on a three point scale with normal looking appendix graded as 1, inflamed appendix as grade 2 and grossly inflamed appendix with periappendicular fluid as grade 3. Subsequently, sonographic and operative findings were compared. Data of all patients was collected on a pre-designed data form. Patients were followed up for 6 months post operatively or till their repatriation to home country. Surgical findings were considered gold standard to assess diagnostic accuracy of sonography.

Statistical Package for Social Sciences (IBM SPSS) version 20.0 was used to analyse data. Relevant descriptive statistics i.e. frequency and percentage was estimated for age, gender, demographic details as well as categorical grouped variables. Cohen weighted $\mathrm{k}$ coefficient was applied using Microsoft Excel with add on Analyse it to verify agreement between radiological and operative findings. Values between 0.61 and 0.80 were considered good agreement. Positive and negative predictive values were calculated using $2 \times 2$ table.

\section{RESULTS}

During the study period, 51 patients were admitted with clinical suspicion of acute appendicitis. Out of 51 patients $46(90.2 \%)$ were males and $5(9.8 \%)$ were females. Mean age of the patients was $32.3 \pm 7.3$ years. Among the study subjects, $15(29.4 \%)$ patients were from Nigeria followed by $12(23.5 \%)$ from Pakistan, 7 (13.7\%) from 
Egypt and $4(7.8 \%)$ patients were from Nepal (figure).

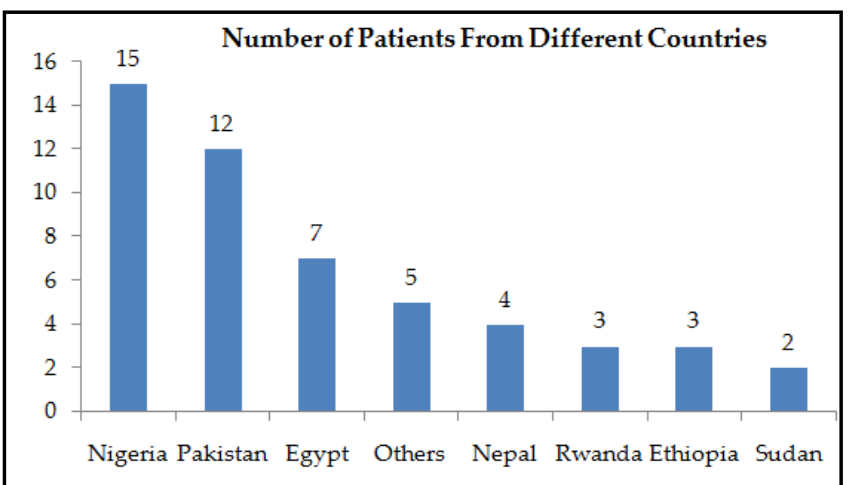

Figure: Demographic details of patients. (Others $=1$ patient each from Bangladesh, Jordan, South Africa, Tanzania and Togo).

After investigations all clinically suspected patients were subjected to ultrasonography followed by surgery. The sonographic findings were detected positive for acute appendicitis in 40 $(78.4 \%)$ and negative in $11(21.6 \%)$ out of 51 . All

Table: Sonographic diagnosis compared with surgical findings in patients who underwent surgery.

\begin{tabular}{l|c|c|c}
\hline \multirow{2}{*}{ Surgery } & \multicolumn{2}{|c|}{ Sonography } & \multirow{2}{*}{ Total } \\
\cline { 2 - 3 } & $\begin{array}{c}\text { Positive } \\
\mathbf{n}(\mathbf{\%})\end{array}$ & $\begin{array}{c}\text { Negative } \\
\mathbf{n}(\mathbf{( \% )}\end{array}$ & $\mathbf{n}$ \\
\hline Positive & $39(76.5)$ & $4(7.8)$ & $43(84.3)$ \\
\hline Negative & $1(2.0)$ & $7(13.7)$ & $8(15.7)$ \\
\hline Total & $40(78.4)$ & $11(21.6)$ & $51(100)$ \\
\hline
\end{tabular}

\begin{tabular}{l|c}
\hline Table-II: Alvarado score. & Points \\
\hline Findings & 1 \\
\hline $\begin{array}{l}\text { Migrating Pain to the right lower } \\
\text { quadrant }\end{array}$ & 1 \\
\hline Nausea / Vomiting & 1 \\
\hline Anorexia & 2 \\
\hline Tenderness & 1 \\
\hline Rebound tenderness & 1 \\
\hline Body temperature $\geq 37.3^{\circ} \mathrm{C}$ & 2 \\
\hline Leukocytosis & 1 \\
\hline Shift to left of Neutrophils & \\
\hline Score: & \\
0-4: Less likely to be acute appendicitis. Outdoor follow up. \\
5-6: Possible acute appendicitis. Indoor investigations. \\
7-8: High probability of acute appendicitis. \\
9-10: Definite acute appendicitis. Needs surgical exploration.
\end{tabular}

Fifty-one patients underwent surgery. The surgical findings were positive for appendicitis in
43 patients $(84.3 \%)$. Four patients with negative sonographic findings did have acute appendicitis and one patient with positive sonography had normal appendix per-operative (table). There was good agreement between sonographic findings and surgical findings, which was statistically significant. ( $\mathrm{KW}=0.70$ [95\% CI, 0.49-0.91]). Out of 7 patients with negative sonograhic and operative findings for acute appendicitis, ovarian cyst was found in 1 patient. Ultrasonography showed a negative predictive value of $85.7 \%$ and a positive predictive value of $90.9 \%$. Diagnostic accuracy of ultrasonography was $90.2 \%$.

\section{DISCUSSION}

Acute appendicitis is the most common cause of acute abdominal pain in patients presenting in ER that requires surgical treatment. The peak incidence of acute appendicitis is seen in the second and third decade of life and it is uncommon before the age of 5 and after the age of 50 years 4 . Before puberty, the incidence of acute appendicitis is equal among males and females. Teenager and young males are affected more commonly than females and this greater incidence in males decline after the age of $25^{12}$. Wide geographic, racial and occupational variations reported in the incidence of acute appendicitis are probably due to differences in dietary fibre consumption.

The acute appendicitis is diagnosed clinically; however, there is $10 \%$ to $30 \%$ incidence of unnecessary appendicectomies for an incorrect diagnosis of appendicitis ${ }^{13}$. The presentation of acute appendicitis can be confusing and clinical features may be subtle making it one of the most common diagnostic dilemmas in clinical practice. Due to overlapping symptoms and clinical signs intussusception, mesenteric adenitis, viral gastroenteritis and ovarian conditions in female patients may be confused with appendicitis. The difficult clinical diagnosis of appendicitis is assisted by a number of clinical and laboratory based scoring systems like the most widely used Alvarado Score (MANTRELS) and Appendicitis Inflammatory Response Score ${ }^{14,15}$. 
After clinical examination and laboratory investigations, patients with an equivocal score benefit from imaging studies to reduce the rate of negative appendicectomy. Imaging plays a key role in the evaluation of all cases of acute abdomen and the ideal imaging test for such cases is the one that is safe, fast, inexpensive, reproducible and readily available. The most commonly used imaging tests in evaluation of possible appendicitis are ultrasonography and computed tomography (CT) scan.

Abdominal ultrasound examination has become a valuable tool for diagnosis in acute abdomen. Ultrasound examination has diagnostic accuracy in excess of 90 percent in children, thin adults and females with suspected gynaecological pathology10,16. Graded compression ultrasonography is inexpensive, can be performed rapidly without contrast medium, and is safe in pregnant patients ${ }^{17}$. On ultrasound, the appendix is seen as a blind-ending, aperistaltic bowel loop in the right lower abdomen. Increased anteriorposterior diameter of $>6 \mathrm{~mm}$, thickening of the appendicular wall and the presence of periappendicular fluid are highly suggestive of appendicitis. Whereas an easily compressible appendix with diameter measuring $<5 \mathrm{~mm}$ excludes the diagnosis of appendicitis ${ }^{13}$. In a metaanalysis, Doria described the overall sensitivity of ultrasound as $88 \%$ and $83 \%$ and its specificity as $94 \%$ and $93 \%$, for children and adults, respectively ${ }^{18}$.

Ultrasound has several advantages and disadvantages as a diagnostic modality for appendicitis. The disadvantages of ultrasound include patient discomfort evoked by transducer pressure, operator dependence and limited use in obese adults. The advantages of ultrasonography include non-invasiveness, short acquisition time, lack of radiation exposure, safe, relatively inexpensive, and widely available ${ }^{19}$. Other advantages include excellent imaging modality for the reproductive organs and the potential for discovering other causes of abdominal pain. For these reasons, it is especially useful in children and women of childbearing age to minimize radiation exposure to reproductive organs. In our study, ovarian cyst was found in 1 patient. The literature shows that the ultrasonography can be performed by non-radiologist emergency physicians with specificities of $90 \%$ and higher depending on the age of the patient and equipment used ${ }^{1}$.

The computed tomography (CT) scan as a diagnostic modality for appendicitis has accuracy of $93 \%$ to $98 \%$ in a number of studies because of its ability to show normal appendix more reliably and with greater consistency than ultrasonography $^{8}$. With high-resolution CT scan, the inflamed appendix appears dilated $(>5 \mathrm{~mm})$ and thick walled with signs of inflammation in the form of periappendicular fat stranding, thickened mesoappendix and free fluid. Unlike ultrasonography, intraperitoneal fat in obese patients actually improves the diagnostic accuracy of CT scan for appendicitis ${ }^{20}$. In older patients with diagnostic uncertainty and differential diagnosis of diverticulitis and neoplasm Contrast-enhanced CT scan is the most useful diagnostic tool. Despite the potential usefulness in reducing negative appendectomies, the significant disadvantages of the CT scan are expensiveness, significant radiation exposure, limited use during pregnancy and allergy to contrast agents ${ }^{21}$.

Several studies have compared the use of ultrasonography and CT scan in the diagnosis of acute appendicitis. Wiersma et al 22 reported visualisation of normal appendix in $82 \%$ of asymptomatic children on ultrasonography. In most of the studies, visualization of appendix is included in diagnostic criteria. But like a few other studies we considered ultrasound findings positive when secondary signs of appendix were present even if appendix was not visualised ${ }^{23}$. The findings were considered negative if appendix and secondary signs of appendix were absent thus excluding acute appendicitis on the basis of negative ultrasonography. Using these criteria, the NPV was $85.7 \%$, similar to results in prior studies ${ }^{24}$. Three patients with acute appendicitis in our study had false-negative and one patient had false positive sonographic findings. Retrocecal and retroileal appendixes are difficult to visualize, whereas anterior appendixes are relatively easy to identify. In 
our study, 1 patient who had falsepositive sonography has ruptured right ovarian cyst with free fluid in the pelvis and right iliac fossa. The PPV in our study $(90.9 \%)$ was also comparable with other studies 10,24 . Our study focused mainly on the screening value of sonography, with the sonograms interpreted in a manner to avoid missing any cases with positive findings, subtle but nonspecific signs that might have indicated acute appendicitis, such as fluid in the right paracolic gutter, were interpreted as positive results (grade 3 sonographic findings).

Our study was limited mainly to United Nations Force serving in UNAMID Dafur, Sudan and generally to IDPs in Nyala. This study was also limited by non availability of CT scan and histopathology at level III hospital, and higher operator dependency for ultrasonographic examination. However, our study was aided by the screening protocol at our institution for exclusion of appendix. In conclusion, sonography was found to have a high NPV (85.7\%) in our study, for the exclusion of acute appendicitis even if the appendix was not visualized. With increased workload, time allocation for each patient is decreased and it becomes very difficult to perform graded compression for localization of appendix. The role of sonography in screening algorithms for the evaluation of suspected acute appendicitis is supported, particularly in young female patients for whom the gonadal radiation dose should be kept to a minimum. However, further imaging can be performed if clinical signs and symptoms become worse or strongly suggest appendicitis.

\section{CONCLUSION}

Sonography using graded compression has high diagnostic accuracy for acute appendicitis. Our study also showed that sonography has high PPV, NPV and diagnostic accuracy. Therefore, sonography should be used as a primary screening tool in the algorithm of evaluation of acute appendicitis. Further imaging like CT scan should be reserved for patients with equivocal sonography and persistent clinical signs and symptoms.

\section{CONFLICT OF INTEREST}

This study has no conflict of interest to be declared by any author.

\section{REFERENCES}

1. Douglas CD, Macpherson NE, Davidson PM, Gani JS. Randomised controlled trial of ultrasonography in diagnosis of acute appendicitis, incorporating the Alvarado score. Brit Med J 2000; 321(7266): 919.

2. Richardson,William S. The evolution of early appendectomy as standard treatment from appendicitis: what we can learn from the past in adopting new medical therapies. Am Surg 2015; 81(2): 159-63.

3. Korner H, Sondenaa K, Soreida JA, Nysted A, Vatten L. The history is important in patients with suspected acute appendicitis. Dig Surg 2000; 17: 364-69.

4. Gwynn LK. The diagnosis of acute appendicitis: clinical assessment versus computed tomography evaluation. Am J Emerg Med 2001; 21(2): 119-23.

5. Ferris M, Quan S, Kaplan BS. The global incidence of appendicitis: a systematic review of population-based studies. Ann Surg 2017; 266(2): 237-41.

6. Krajevski S, Brown J, Phang PT, Raval M, Brown JC. Impact of computed tomography of the abdomen on clinical outcomes in patients with acute right lower quadrant pain: a metaanalysis. Can J Surg 2011; 54(1): 43-53.

7. Subash KC, Abhijit De, Pathak M, Sathian B. Diagnostic role of ultrasonography in acute appendicitis: a study at a tertiary care hospital. Am J Public Health Res 2015; 3(5A): 23-28.

8. Al-Khayal KA, Al-Omran MA. Computed tomography and ultrasonography in the diagnosis of equivocal acute appendicitis. A meta-analysis. Saudi Med J 2007; 28(2): 173-80.

9. Aspelund G, Fingeret A, Gross E, Kessler D, Keung C, Thirumoorthi A, et al. Ultrasonography/MRI versus CT for diagnosing appendicitis. Pediatrics 2014; 133(4): 586-93.

10. Van Atta AJ, Baskin HJ, Maves CK, Rollins MD, Bolte RG, Mundorff MB, et al. Implementing an ultrasound-based protocol for diagnosing appendicitis while maintaining diagnostic accuracy. Pediatr Radiol 2015; 45(5): 678-85.

11. Obsa MS, Adema BG, Shanka GM, Azeze GA, Fite RO. Prevalence of acute appendicitis among patient admitted for acute abdomen in Ethiopia: Systematic review and meta-analysis. Int J Surg Open 2020; 26(1): 154-60.

12. Mardan MA, Mufti TS, Khattak IU, Chilkunda N, Alshayeb AA, Mohammad AM, et al. Role of ultrasound in acute appendicitis. J Ayub Med Coll Abbottabad 2007; 19(3): 72-79.

13. Bachur RG, Callahan MJ, Monuteaux MC, Rangel SJ. Integration of ultrasound findings and clinical score in the diagnostic evaluation of pediatric appendicitis. J Pediatr 2015; 166(5): 1134-39.

14. Alfraih Y, Postuma R, Keijzer R. How do you diagnose appendicitis? An international evaluation of methods. Int J Surg 2014; 12(5): $67-70$.

15. Teicher I, Landa B, Cohen M, Cabnick LS, Wise L. Scoring system to aid in the diagnosis of appendicitis. Ann Surg 1983; 198(6): 753-59.

16. Incesu L, Yazicioglu AK, Selcuk MB, Ozem N. Contrast-enhanced power-doppler US in the diagnosis of acute appendicitis. Eur J Radiol 2004; 50: 201-09.

17. Davidson PM, Douglas CD, Hosking CS. Graded compression ultrasonography in the assessment of the "tough decision" acute abdomen in childhood. Pediatr Surg Int 1999; 15: 32-35. 
18. Doria AS, Moineddin R, Kellenberger CJ, Epelman M, Beyene J, Schuh S, et al. US or CT for diagnosis of appendicitis in children and adults? A Meta-Analysis. Radiology 2006; 241(1): 83-94.

19. Parker L, Nazarian LN, Gingold EL, Palit CD, Hoey CJ, Frangos AJ. Cost and radiation savings of partial substitution of ultrasound for CT in appendicitis evaluation: a national projection. Am J Roentgenol 2014; 202(1): 124-35.

20. Kaewlai R, Lertlumsakulsub W, Srichareon P. Body mass index, pain score and Alvarado score are useful predictors of appendix visualization at ultrasound in adults. Ultrasound Med Biol 2015; 41(1): 1605-11.

21. Van Randen A, Bipat S, Zwindermann AH, Ubbink DT, Stoker J, Boermeester MA. Acute appendicitis: Meta-analysis of diag- nostic performance of CT and graded compression US related to prevalence of disease. Radiology 2008; 249(1): 97-106.

22. Wiersma F, Toorenvliet BR, Bloem JL, Allema JH, Holscher HC. US examination of the appendix in children with suspected appendicitis: the additional value of secondary signs. Eur Radiol 2009; 19(2): 455-61.

23. Estey A, Poonai N, Lim R. Appendix not seen: the predictive value of secondary inflammatory sonographic signs. Pediatr Emerg Care 2013; 29(4): 435-39.

24. Pinto F, Pinto A, Russo A, Coppolino F, Bracale R, Fonio P, et al. Accuracy of ultrasonography in the diagnosis of acute appendicitis in adult patients: review of the literature. Crit Ultrasound J 2013; 5(Suppl-1): S2-9. 